\title{
The Effect of Polyethylene Glycol on the Toxicity Properties of Functionalized Carbon Nanotubes with the Variations of Hydrochloric Acid (HCl)
}

\author{
Praswasti Pembangun Dyah Kencana Wulan,,a , Nadia Salsabila ${ }^{2, b}$ \\ ${ }^{1}$ Chemical Engineering Department, Faculty of Engineering, Universitas Indonesia, Depok, 16424, Indonesia . \\ ${ }^{2}$ Sustainable Energy Laboratory Chemical Engineering Department, Faculty of Engineering, Universitas Indonesia, \\ Depok, 16424, Indonesia. \\ ${ }^{1}$ ORCID: 000-0002-9272-262X
}

\begin{abstract}
Carbon nanotubes (CNT) are one of the nanotechnologies in the drug delivery system (DDS) because it has high drug loading and targeting delivery capabilities. Pristine CNT are toxic and hydrophobic, so they don't meet the requirements of the DDS. Other researchers have performed CNT functionalization with polyethylene glycol (PEG) by observing cell viability and tumor size without performing toxicity tests. Previous investigators performed a toxic test, but the toxicity of functionalized CNT is (CNTf) still high. This study aims to obtain the effect of the (PEG) addition through secondary functionalization of the toxicity of CNTf. CNT is covalently functionalized through oxidation by $\mathrm{HNO}_{3} / \mathrm{H}_{2} \mathrm{SO}_{4}$. Variations made are the addition of $\mathrm{HCl} 8 \mathrm{M}, \mathrm{HCl} 10 \mathrm{M}$, and without $\mathrm{HCl}$ addition with sonication at $40^{\circ} \mathrm{C}$ for 4 hours, followed by PEG addition. CNTf was characterized by FTIR, TGA, UV-Vis Spectroscopy, dispersion tests, and BSLT. The results showed that samples with the PEG addition had formed C-O-C groups originating from PEG. CNTf sample with the $\mathrm{HCl} 8 \mathrm{M} / \mathrm{PEG}$ addition produced the highest percentage solubility, which is $49.71 \%$, and the highest $\mathrm{LC}_{50}$ toxicity value of $993.77 \mathrm{ppm}$. These results indicate that PEG can increase CNT solubility and reduce CNT toxicity. The highest degree of functionalization was generated by CNTf with the PEG addition for 12 hours continuously and without the $\mathrm{HCl}$ addition, which is $0.028 \%$. However, CNTf with the PEG addition showed the formation of aggregates in the 29th-day dispersion test.
\end{abstract}

Keywords: CNT, CNT characterization, CNT functionalization, CNT toxicity

\section{INTRODUCTION}

Cancer treatment generally uses chemotherapy, which has the effect of damaging healthy cells in normal tissues and metabolism of drugs that are unable to reach the tumor site. One of the solutions to overcome the above problems is a nanotechnology approach. Nanomedicine has high selectivity and effectiveness in drug targeting. This approach makes nanomedicine avoid metastasis or damage to healthy cells around the target cell [1]. Carbon nanotubes (CNT) are one of the nanotechnologies that can be drug delivery agents due to their high loading capacity and targeting delivery without reacting with other cells [2].

Pristine has hydrophobic and non-biodegradable characteristics that make CNT challenging to disperse in water [3] so that they cannot meet drug delivery requirements. To overcome this is to make modifications or functionalization on the surface of the CNT. CNT functionalization can be done through 2 methods, namely covalent and non-covalent. Covalent functionalization is more suitable for drug delivery systems because it has strong bonds between carbon molecules and functional groups, controlled, and allows for the multi-functionalization of CNT [4]. Covalent functionalization can be carried out through surface oxidation of CNT with strong acids that produce carboxyl groups, thereby increasing CNT solubility in polar solvents [4].

Functionalization of the CNT using strong acids such as nitrates and sulfates will oxidize the CNT to carboxylic and hydroxyl groups. This process makes the CNT dispersed and tends to increase the biocompatibility properties of the CNT. [5]. $\mathrm{HCl}$ plays a role in removing amorphous carbon and catalysts of $\mathrm{Ni}$ residues formed in the CNT manufacturing process.

The residual metal catalyst will react with $\mathrm{HCl}$ to form metal chloride. This metal can easily be separated from the CNT by operating the separation of the solution from the solids. [6]. Purification procedures such as oxidation will remove impurities in CNT but can cause some carbon framework imperfections that can trigger toxic effects on CNT [7].

The addition of PEG to a functionalized CNT is to protect the CNT surface structure damage so that it will protect the CNT surface from aggregation formation [8] and reduce the toxicity of the CNT. Besides, PEG can improve biocompatibility, dispersibility, and stability and CNT properties [ 9]. PEG is attached to the entire surface of the CNT so that it produces less damage to the CNT surface and thus can maintain the intrinsic nature of CNT [10]. C-O-C bonds are polar ether functional groups so that they can improve the hydrophilic nature of CNT [11]. Previous researchers have performed CNT functionalization using strong acids consisting of $\mathrm{HNO}_{3}$, $\mathrm{H}_{2} \mathrm{SO}_{4}$, and $\mathrm{HCl}$ [12]. They reported that the strong acid can increase the CNT dispersibility and solubility but still cannot reduce the CNT toxicity. This study aims to function the CNT with the addition of PEG as a secondary functionalization. This treatment is specific to overcome the toxic nature of the CNT to meet the standard drug delivery system (DDS).

\section{EXPERIMENT}

The CNT used is a Multi-Walled Carbon Nanotube (MWCNT) with a purity of $98 \%$. This research was started from the oxidation of CNT by $\mathrm{HNO}_{3} / \mathrm{H}_{2} \mathrm{SO}_{4}(\mathrm{v} / \mathrm{v}=3: 1)$ mixture solution through the sonication process at $40^{\circ} \mathrm{C}$ for 4 hours. Samples were allowed to stand for 24 hours after sonication. The method 
of the $\mathrm{HCl}$ addition is carried out on samples with variations concentration of $\mathrm{HCl}$. Furthermore, the filtration and washing process is carried out until the $\mathrm{pH}$ reaches neutral (6.5-7). After the $\mathrm{pH}$ is neutral, the samples are dried to dry. The variation of adding PEG to the dried sample can be started by mixing CNT with PEG / Aquades solution. Sonication of the mixture for 3 minutes and stirring for 12 hours was carried out continuously and periodically to ensure that PEG adhered to the CNT. The samples were allowed to stand for 12 hours and followed by a filtration and washing process to remove the remaining PEG that could not stick to the CNT surface. The final step is drying the sample before characterization.

Functionalized CNT was characterized using FTIR to determine the presence of functional groups formed on the CNT surface, UV-Vis test to determine the percentage of CNT solubility, TGA to assess the degree of CNT functionalization, BSLT to determine LC50 values as parameters of CNT toxicity levels, and dispersion tests to determine CNT dispersibility in the solvent media.

\section{RESULT AND DISCUSSIONS}

FTIR characterization was carried out to identify hydrophilic functional groups formed on the surface of the CNT. Fig. 1 shows that all functionalized CNT samples have formed hydroxyl $(\mathrm{O}-\mathrm{H})$ functional groups in the wavelength range of $3300-3600 \mathrm{~cm}^{-1},(\mathrm{C}=\mathrm{O})$ in the wavelength range of $1600-1700$ $\mathrm{cm}^{-1},(\mathrm{C}-\mathrm{O})$ in the wavelength range of $1140-1188 \mathrm{~cm}^{-1}$, and $(\mathrm{C}-\mathrm{H})$ in the wavelength range of $850-1300 \mathrm{~cm}^{-1}$. This functional group shows polar functional groups, which can increase the CNT hydrophilic.

All samples with variations in the addition of PEG have formed $\mathrm{C}-\mathrm{O}-\mathrm{C}$ functional groups in the wavelength range of $1050-1250 \mathrm{~cm}^{-1}$ and $\mathrm{CH}_{2}$ functional groups in the wavelength range of $1450 \mathrm{~cm}^{-1}$. These results show that functional groups originating from PEG have successfully attached to the surface of the CNT. C-O-C bonds are ether functional groups that are polar so that they can improve the hydrophilic nature of CNT. The C-O-C bond is ether oxygen that will bind hydrogen from water. The $\mathrm{O}-\mathrm{H}$ bond between PEG and water makes PEG able to dissolve well in water [13].

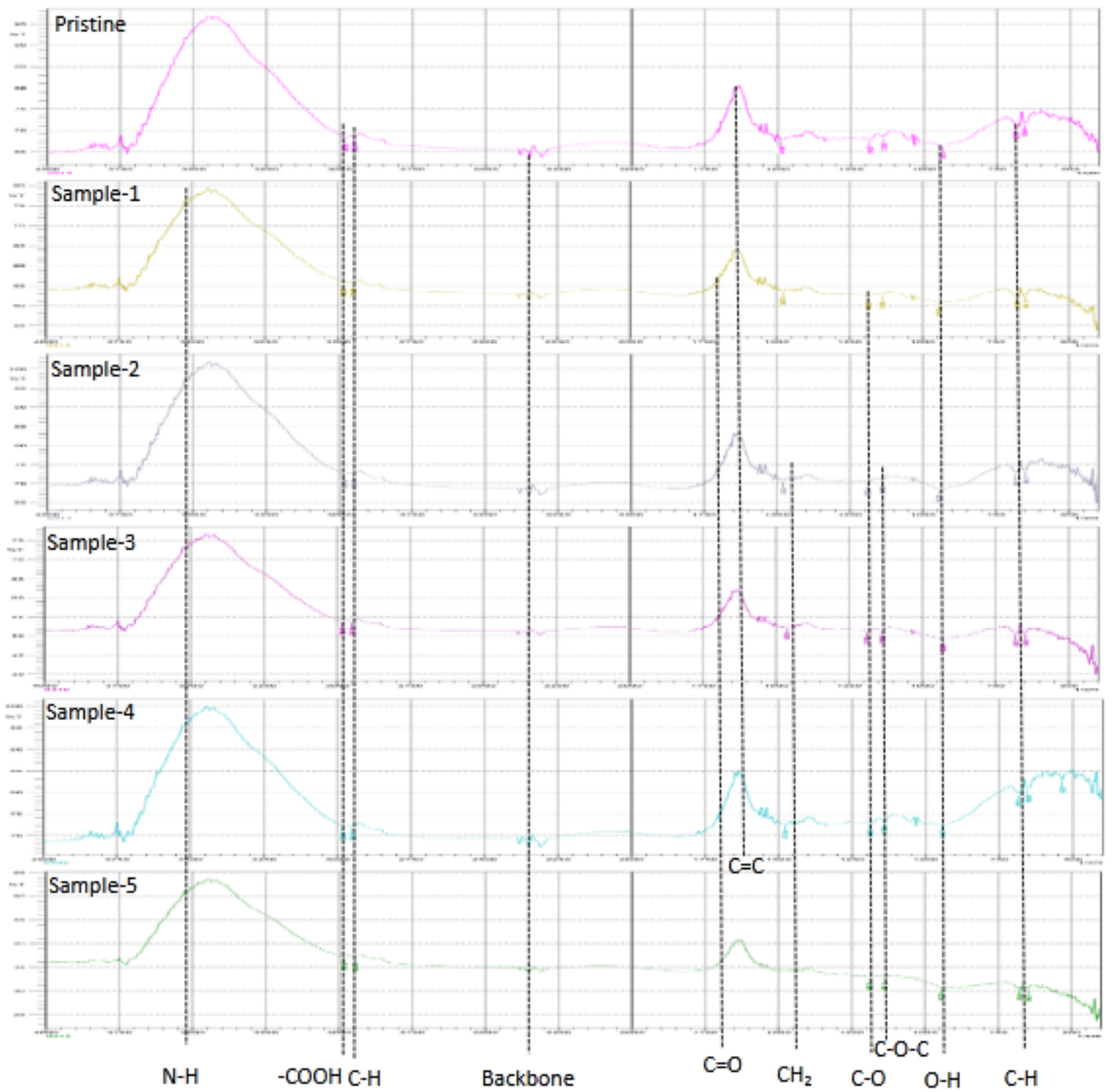

Figure 1. FTIR Characterization Results 
International Journal of Engineering Research and Technology. ISSN 0974-3154, Volume 13, Number 10 (2020), pp. 2541-2545

(C) International Research Publication House. https://dx.doi.org/10.37624/IJERT/13.10.2020.2541-2545

UV-Vis characterization was carried out to determine the solubility of CNT. The absorbance parameters of the test were obtained from UV-Vis spectrophotometry as in Table 1.

Table 1. UV-Vis Characterization Results

\begin{tabular}{|l|c|c|c|}
\hline \multicolumn{1}{|c|}{$\begin{array}{c}\text { Sample } \\
\text { Variations }\end{array}$} & $\begin{array}{c}\text { Sample } \\
\text { Name }\end{array}$ & Absorbance & $\begin{array}{c}\text { \% C content } \\
\text { in Aquades }\end{array}$ \\
\hline Pristine & Pristine & 0.6399 & 22.86 \\
\hline CNT/10M HCl & Sample-1 & 0.8676 & 31.00 \\
\hline CNT/8M HCl/PEG & Sample-2 & 1.3915 & 49.71 \\
\hline CNT/10M HCl/PEG & Sample-3 & 1.2548 & 44.83 \\
\hline $\begin{array}{l}\text { CNT/PEG 12 hours } \\
\text { periodically }\end{array}$ & Sample-4 & 1.0673 & 38.13 \\
\hline $\begin{array}{l}\text { CNT/PEG 12 hours } \\
\text { continuously }\end{array}$ & Sample-5 & 1.1368 & 40.61 \\
\hline
\end{tabular}

Based on the calculation of $\mathrm{C}$ content percentage in Table 1, the pristine has a solubility of $22.86 \%$, which indicates that only $22.86 \%$ can be dissolved in distilled water. In this case, another $77.14 \%$ is insoluble and will precipitate, thus showing that the CP sample has low solubility and still hydrophobic. Sample-1, sample-2, sample-3, sample-4, and sample-5 show an increase in solubility percentage with a magnitude of values by $31 \%$, $49.71 \%, 44.83 \%, 38.13 \%$ and $40.61 \%$, respectively. Sample-2 which is treated with $8 \mathrm{M} \mathrm{HCl}+\mathrm{PEG}$ variation, had the highest solubility compared to other samples. This result shows that the sample-3 has the best functional group attachment (C-O-C bond), as seen as Fig. 1. That treatment produces the most stable covalent bond, which is almost $50 \%$ dissolved in distilled water [12].

TGA is carried out to calculate the degree of functionalization by quantifying the number of functional groups contained in CNT through the decomposition of CNT masses at a specific temperature.

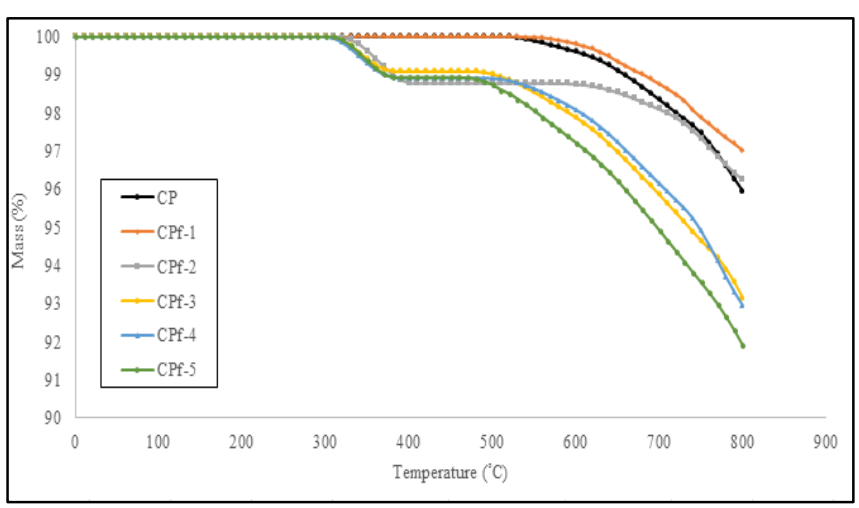

Figure 2. TGA Characterization Results

Fig. 2 shows a mass decrease in all samples with a degradation temperature range of $40-800^{\circ} \mathrm{C}$. The pristine $(\mathrm{CP})$ shows a mass decrease that occurred at $510^{\circ} \mathrm{C}$. Functionalized CNT samples consisting of samples-1 (CPf-1), sample-2 (CP-2), sample-3 (CP-3), sample-4 (CP-4), and sample-5 (CP-5) experienced a mass decrease at temperatures of $260^{\circ} \mathrm{C}, 310^{\circ} \mathrm{C}, 300^{\circ} \mathrm{C}, 300^{\circ} \mathrm{C}$ and $310^{\circ} \mathrm{C}$, respectively. The mass decrease in the functionalized samples that occur at temperatures lower than the temperature of the mass decrease in pristine indicates the damage that occurs on the surface of the CNT. CNT decomposition that occurs in the temperature range of 250 $500^{\circ} \mathrm{C}$ is caused by the decomposition of functional groups contained in the CNT [12].

Functionalized CNT samples with variations in the addition of PEG consisting of sample-2 (CPf-2), sample-3 (CPf-3), sample-4 (CPf-4), and sample-5 (CPf-5) experienced a significant mass decrease in the temperature range of 310 $420^{\circ} \mathrm{C}$ which didn't occur in the decomposition of pristine and sample-1 (CPf-1). These results indicate that the mass transfer with PEG has been successfully attached to the CNT surface. The mass loss induced by PEG occurs in the temperature range $310-480^{\circ} \mathrm{C}$, which has been proven by several predecessors [14]. Estimates of the degree of functionalization from the percentage decomposition of CNT samples, as shown in Table 2.

Table 2. The results of the calculation of the degree of functionalization

\begin{tabular}{|l|c|c|c|c|}
\hline Sample & $\begin{array}{c}\text { Mass loss of } \\
\text { the } \\
\text { functional } \\
\text { groups (\%) }\end{array}$ & $\begin{array}{c}\text { Mass } \\
\text { loss of } \\
\text { CNT } \\
(\%)\end{array}$ & $\begin{array}{c}\text { Mass } \\
\text { loss } \\
\text { total } \\
(\%)\end{array}$ & $\begin{array}{c}\text { Degree of } \\
\text { functionalization } \\
(\%)\end{array}$ \\
\hline Sample-1 & 0.013 & 2.981 & 2.994 & 0.001 \\
\hline Sample-2 & 1.240 & 2.530 & 3.770 & 0.025 \\
\hline Sample-3 & 1.000 & 5.870 & 6.869 & 0.020 \\
\hline Sample-4 & 1.103 & 5.958 & 7.061 & 0.024 \\
\hline Sample-5 & 1.270 & 6.837 & 8.108 & 0.028 \\
\hline
\end{tabular}

Table 2 shows that the sample- 5 had the highest percentage of the degree of functionalization, which is $0.028 \%$. The trend of increasing the degree of functionalization indicates that the addition of PEG is useful. The total mass reduction in the sample- 2 produced the lowest value after the sample- 1 caused by the low CNT mass decrease value in the sample- 2 at above $500^{\circ} \mathrm{C}$ temperature.

Thermal degradation, which causes a mass reduction at temperatures above $500^{\circ} \mathrm{C}$, can be related to thermal oxidation of irregular carbon residues in CNT, such as amorphous carbon remaining in CNT [15]. The lack of degradation that occurs in sample-2 in temperature ranges over $500^{\circ} \mathrm{C}$ indicates the absence of irregular carbon in the sample [16]. The increase in the degree of functionalization in sample 5 in showing that continuous stirring for 12 hours was useful in attaching PEG to the CNT surface.

Based on the results of the FTIR, UV-Vis, and TGA characterization tests, the toxicity test can be carried out. Toxicity assays were carried out through BSLT in-vitro cytotoxic testing through $\mathrm{LC}_{50}$ values in all CNT samples. $\mathrm{LC}_{50}$ value is the number of numbers that determine the category of toxic properties of an ingredient. The $\mathrm{LC}_{50}$ values of the sample 
are summarized in Table 3.

Table 3. BSLT Results

\begin{tabular}{|l|c|l|}
\hline Sample & LC $_{\mathbf{5 0}}$ value $(\mathbf{p p m})$ & Category \\
\hline Pristine & 554.07 & Moderate Toxic \\
\hline Sample-1 & 162.43 & Moderate Toxic \\
\hline Sample-2 & 993.77 & Moderate Toxic \\
\hline Sample-3 & 477.13 & Moderate Toxic \\
\hline Sample-4 & 199.66 & Moderate Toxic \\
\hline Sample-5 & 283.13 & Moderate Toxic \\
\hline
\end{tabular}

Table 3 shows the results of the BSLT cytotoxic test from all samples, which are categorized as moderate toxic $\left(\mathrm{LC}_{50} 30-\right.$ $1000 \mathrm{ppm})$. The sample-2 with the variation of $\mathrm{HCl} 8 \mathrm{M}+\mathrm{PEG}$ showed the best results, with an $\mathrm{LC}_{50}$ value of $993.77 \mathrm{ppm}$. These results indicate that $50 \%$ of the total shrimp larvae died at a concentration of CPf-2 sample of $993.77 \mathrm{ppm}$. The $\mathrm{LC}_{50}$ value of the functionalized CNT sample, which is lower than the $\mathrm{LC}_{50}$ value of the pristine. This result shows that the functionalization of CNT with acids can increase the toxicity of CNT. Therefore, it is necessary to add a polymer that can reduce the toxicity of pristine and the toxicity that results from acid functionalization. The addition of PEG to functionalized CNT samples can reduce the toxicity from pristine.

The dispersion test is carried out to observe the CNT dispersibility through the stability of the CNT suspension during the dispersion process by measuring the height of CNT suspension formed in the dispersion media. After being allowed to stand for 1 hour to 1 day since the sonication process, pristine and sample- 1 began to show a decrease in suspension while all samples with the addition of PEG still showed suspension stability. All samples with the addition of PEG formed a suspension at the bottom of the bottle on day 29. Pristine will experience the worst reduction in suspension among other samples. This result is because pure CNT has van der Waals bonds with a robust tensile strength so that the CNT will quickly become bundles. This formation indicates that the appearance of aggregates and tangled tissue on the CNT causes the CNT not to be able to spread appropriately in the solvent (aquades) [12]. This result is following the results of FTIR, which showed that the transmittance intensity obtained by the CP sample was higher among all CPf samples.

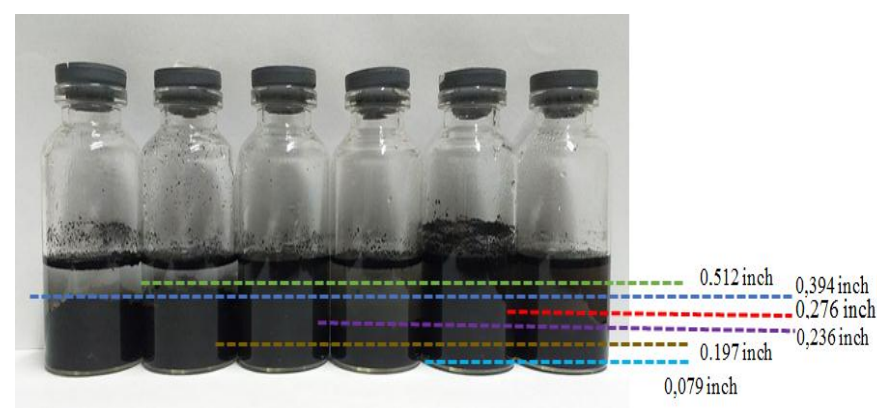

Figure 3. Dispersion Tests Characterization Results (29 days)
The darker color of the solution in the sample- 2 and sample- 4 was still seen among the solutions in the other samples. These results show that some $\mathrm{CNT}$ particles are still well dispersed in distilled water, but dominant CNT particles have formed a suspension at the bottom of the bottle. Formation of suspension at the bottom of the bottle due to the formation of aggregates on the CNT. The formation of aggregates in the PEG solution is due to the influence of high temperatures $\left(\mathrm{t}>30^{\circ} \mathrm{C}\right)$. This aggregate formation comes from hydrophobic interactions that occur at high temperatures around it in a liquid solution [13]. This is because PEG has an ethylene $\mathrm{CH}_{2}$ functional group which is a hydrophobic functional group of PEG that makes PEG form aggregates in polar solvents at high temperatures, as seen as Fig. 1.

\section{CONCLUSION}

The addition of PEG was able to increase the solubility of functionalized CNT. Variation of CNT with $8 \mathrm{M} \mathrm{HCl}$ and addition of PEG had the highest solubility value of $49.71 \%$ and the highest degree of functionalization of $0.025 \%$ and LC50 of $993.77 \mathrm{ppm}$. Future studies need to make variations in determining the time required for PEG attachment to the CNT to minimize the toxicity of the CNT.

\section{ACKNOWLEDGMENTS}

The authors would like to thank for the research funding from The Directorate General of Higher Education, Indonesian Ministry of National Education under Penelitian Dasar Unggulan Perguruan Tinggi (PDUPT) with contract number NKB-1657/UN2.R3.1/HKP.05.00/2019.

\section{REFERENCES}

[1] Sanginario, A., Miccoli, B. \& Demarchi, D., 2017. Carbon Nanotubes as an Effective Opportunity forCancer Diagnosis and Treatment. biosensors, 7(1).

[2] Kushwaha, S.K.S., Ghoshal, S., Rai, A.K. \& Singh, S., 2013. Carbon nanotubes as a novel drug delivery system for anticancer therapy: a review. Brazilian Journal of Pharmaceutical Sciences, 49(4), pp.629-43.

[3] Donaldson, K., Aitken, R., Tran, L., Stone, V., Duffin, R., Forrest, G., Alexander, A., 2006. Carbon Nanotubes: A Review of Their Properties in Relation to Pulmonary Toxicology and Workplace Safety. Toxicological Sciences, 92(1), pp.5-22.

[4] Jain, S., Singh, S.R. \& Pillai, S., 2012. Toxicity Issues Related to Biomedical Applications of Carbon Nanotubes. Journal of Nanomedicine \& Nanotechnology, 3(5).

[5] Madani, S.Y., Tan, A., Dwek, M. \& Seifalian, A.M., 2012. Functionalization of single-walled carbon nanotubes and their binding to cancer cells. International Journal of Nanomedicine, 7, p.905-914.

[6] Hamilton, R.F., Xiang, C., Li, M., Ka, I., Yang, F., Ma, D., Porter, D.W., Wu, N., Holian, Andrij., 2013. 
Purification and sidewall functionalization of multiwalled carbon nanotubes and resulting bioactivity in two macrophage models. Inhal Toxicol, 25(4), pp.199-210.

[7] Simeonova, P.P., 2009. Update on carbon nanotube toxicity. Nanomedicine, 4(4), p.373-375.

[8] Suk, J.S., Xu, Q., Kim, N., Hanes, J., Ensign, L.M., 2016. PEGylation as a strategy for improving nanoparticle-based drug and gene delivery. Adv Drug Deliv Rev., 99, pp.28-51.

[9] Weber, G.E.B., Bosco, L.D., Gonçalves, C.O.F., Santos, A.P., Fantini, C., Furtado, C.A., Parfitt, G.M., Peixoto, C., Romano, L.A., Vaz, B.S., Barros, D.M., 2014. Biodistribution and toxicological study of PEGylated single-wall carbon nanotubes in the zebrafish (Danio rerio) nervous system. Toxicology and Applied Pharmacology, 280(3), p.484-492.

[10] Nie, H., Guo, W., Yuan, Y., Dou, Z., Shi, Z., Liu, Z., Wang, H., Liu, Y., 2010. PEGylation of Double-Walled Carbon Nanotubes for Increasing Their Solubility in Water. Nano Research, 3(2), p.103-109.

[11] Elsayed, M.MA., Mostafa, M.E., Alaaeldin, E., Sarhan, H.AA., Shaykoon, M.ShA., Allam, S., Ahmed, A.RH., Elsadek, B.EM., 2019. Design And Characterisation Of Novel Sorafenib-Loaded Carbon Nanotubes With Distinct Tumour-Suppressive Activity In Hepatocellular Carcinoma. International Journal of Nanomedicine, 14, p.8445-8467.

[12] Pujiastuti, S. \& Wulan, P.P., 2019. The effect of hydrogen peroxide $\left(\mathrm{H}_{2} \mathrm{O}_{2}\right)$ on carbon nanotubes solubility as drug delivery material for cancer with covalent functionalization. 3rd International Symposium of Biomedical Engineering"s Recent Progress in Biomaterials, Drugs Development, and Medical Devices, ISBE 2018. Jakarta, 2019. AIP Publishing.

[13] Ozdemir, C. \& Guner, A., 2007. Solubility profiles of poly(ethylene glycol)/solvent systems, I: Qualitative comparison of solubility parameter approaches. European Polymer Journal, p.43.

[14] Sobhani, Z., Behnam, M.A., Emami, F., Dehghanian, A., Jamhiri, I., 2017. Photothermal therapy of melanoma tumor using multiwalled carbon nanotubes. International Journal of Nanomedicine, 12, p.45094517.

[15] Liang, S., Li, G. \& Tian, R., 2016. Multi-walled carbon nanotubes functionalized with a ultrahigh fraction of carboxyl and hydroxyl groups by ultrasound-assisted oxidation. Journal of Materials Science, 51(7), p.35133524.

[16] Datsyuk, V., Kalyva, M., Papagelis, K., Parthenios, J., Tasis, D., Siokou, A., Kallitsis, I., Galiotis, C., 2008. Chemical oxidation of multiwalled carbon nanotubes. Carbon, 46, pp.833-40. 